\title{
Bioethical Quandaries during the Period of a Pandemic
}

\section{By Fereniki Panagopoulou-Koutnatzi}

Abstract- The period of the pandemic gave rise to multiple and intractable bioethical quandaries arising. In the context of the present study, we will limit ourselves to the examination of the critical issues of mandatory vaccination to manage the pandemic; compulsory medical testing, including temperature screening of the population; the use of experimental drugs; making the wearing of face masks mandatory; and the individual responsibility of each of us for the prevention of the pandemic. Participation stresses the importance of education in bioethics. Accordingly, it supports the notion that, once we win the fight for life and health, constitutional lawyers ought to take the reins and determine that the character of restrictive measures and healthcare policies adopted in periods of crisis, when a prime opportunity for their formulation presented itself because of the pandemic, is one of extraordinariness.

GJHSS-H Classification: FOR Code: 180199p

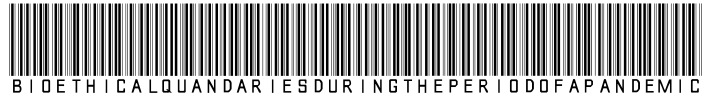

Strictly as per the compliance and regulations of:

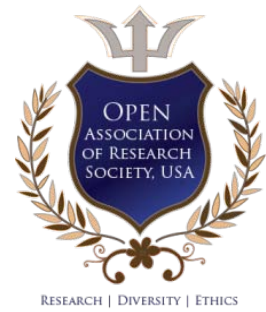

(C) 2021. Fereniki Panagopoulou-Koutnatzi. This research/review article is distributed under the terms of the AttributionNonCommercial-NoDerivatives 4.0 International (CC BY-NC-ND 4.0). You must give appropriate credit to authors and reference this article if parts of the article are reproduced in any manner. Applicable licensing terms are at https://creativecommons.org/ licenses/by-nc-nd/4.0/. 


\title{
Bioethical Quandaries during the Period of a Pandemic
}

\author{
Fereniki Panagopoulou-Koutnatzi
}

\begin{abstract}
The period of the pandemic gave rise to multiple and intractable bioethical quandaries arising. In the context of the present study, we will limit ourselves to the examination of the critical issues of mandatory vaccination to manage the pandemic; compulsory medical testing, including temperature screening of the population; the use of experimental drugs; making the wearing of face masks mandatory; and the individual responsibility of each of us for the prevention of the pandemic. Participation stresses the importance of education in bioethics. Accordingly, it supports the notion that, once we win the fight for life and health, constitutional lawyers ought to take the reins and determine that the character of restrictive measures and healthcare policies adopted in periods of crisis, when a prime opportunity for their formulation presented itself because of the pandemic, is one of extraordinariness.
\end{abstract}

\section{INTRODUCTION}

A II the conversations we used to have from time to time about things that seemed like science fiction are now unfolding before our eyes in quite a threatening manner. Indeed, no matter how much knowledge we may attain, we will always feel small in the face of nature. It is certain that the global pandemic of the new coronavirus stands to prove that reality can surpass any limits of imagination. The need to manage the pandemic gives rise to many questions, some of which call for contemplations about bioethics. The related issues are many in number and difficult to address.

In the context of the present study, we will limit ourselves to the examination of the critical issues of mandatory vaccination to manage the pandemic; compulsory medical testing, including temperature screening of the population; the use of experimental drugs; making the wearing of face masks mandatory; and the individual responsibility of each of us for the prevention of the pandemic.

\section{The Emerging Quandaries}

\section{a) The Issue of Mandatory Vaccination}

The recent coronavirus pandemic and the global irregularity that followed it, coupled with the hope that we are nearing the end of a nightmare that we all had to live through, thanks to the contribution of science, led to the emergence of the debate on whether related vaccination should be made compulsory. This is a matter that has been troubling humanity ever since the invention of vaccines. Following the creation of

Author: Assistant Professor of Constitutional Law, Panteion University, Ph.D (Humboldt), M.P.H. (Harvard), LL.B. and LL.M. (National Kapodistrian University of Athens), Greece.

e-mail: fereniki@panteion.gr vaccines, and up to this day, this issue continues to raise great concerns and heated discussions. Those in favor of compulsory vaccination support that the protection of public health is what is of primary importance and value. On the other hand, those opposed to this notion stress their right to selfdetermination, as well as their reservations concerning the unknowable side effects of vaccines.

The anti-vaccine movement is not a product of the coronavirus. In 1885, for instance, a protest took place in Montreal against the law that made vaccination against smallpox mandatory (James H. Marsh, 2015). Reluctance and anti-vaccine movements occasionally stem from insecurity and mistrust surrounding pharmaceutical companies, which have not, at times, shown the best of conduct, given their subjection to considerable economic interests (Stewart Lyman, 2019). Mistrust is also expressed against science itself (in fact, to be exact, concerning its degree of independence), often precisely because of the existence of scientific controversies. The plurality of dialogue, along with the uncontrollable dissemination of information, has often ended up creating a cacophony. In addition to the above, false news has also contributed to this feeling of mistrust.

The answer on whether vaccination should be mandatory cannot be uniform or apply in all circumstances. Under ordinary circumstances, mandatory vaccination conflicts with the right to selfdetermination (Hellenic Bioethics Committee, Recommendation of 26.05.2015). Such a thing cannot be imposed upon a person when it may bring about, even entirely individually, certain side effects. The rule is that vaccination is recommended, and in some cases highly so, but it is not imposed; therefore, nonvaccination cannot be accompanied by adverse consequences involving exclusion from social life (Vassiliki Mollaki, 2018). Nevertheless, should vaccination be deemed medically required for the immediate protection of public health, and provided this is assessed on the basis of substantiated studies conducted by the medical community, it may be made compulsory in exceptional circumstances, particularly in relation to specified population groups. In any case, however, before doing so it is necessary to exhaust the possibilities of other, milder measures, such as, for example, the extensive provision of information to people concerning the necessity of vaccination.

The issue of mandatory vaccination in the workplace, as a whole, was a matter that was closely considered by the newly founded Hellenic Bioethics and 
Technoethics Committee, which adopted a recommendation on the question of whether vaccination should be mandatory in certain professional groups within the health care sector (Bioethics and Technoethics Committee, Recommendation). The Committee recommended a "graded initiative" approach on the part of the state, consisting of three stages:

The first stage relies on campaigns that are tailored to each professional group that they are addressed to (doctors, nursing professionals, laboratory personnel, health care unit staff, etc.) and involve the provision of targeted information and the raising of awareness regarding voluntary vaccination. Said campaigns are to be based on scientific data that will be continuously updated on the condition of the prior understanding of existing fears and general perceptions on the matter.

The second stage is based on adopting measures of encouragement/discouragement, which could be designed by the state in collaboration with the management of health care units. For example, these may include the facilitation of vaccination appointment bookings, flexibility in terms of working hours on the days of vaccination, granting priority when it comes to taking time off work, or making the wearing of double face masks and personal protective equipment mandatory.

The third stage pertains to making vaccination compulsory as a last resort solution, which must have a specified time horizon and only be applied if all previous measures do not result in considerably increased vaccination coverage. The precise application of such a measure must, on the one hand, be determined pursuant to applicable employment law or public law. On the other hand, it requires that any potential consequences on the allocation of duties and the staffing of the related units, in the event of noncompliance, must also be taken into account in order to prevent shortcomings in their operation or placing a burden on other staff who work there.

The Committee points out that the aforementioned recommendation relates solely to the specific professional groups of staff working in public and private sector health care units, as well as to the personnel of medical units providing care to vulnerable groups. Lastly, the Committee stressed the fact that, with time, the reluctance shown against vaccines for COVID-19, both in relation to specific professional groups but also in terms of the general population, presents a dynamic decrease. This decrease is evidenced by daily data concerning vaccinations in Greece and constitutes a fact that should be taken under serious consideration in implementing the above proposals.

It is understood by its recommendation that the Committee proposes compulsory vaccination as a last resort only for health care workers, which is likely to be avoided given the decrease in the number of vaccine deniers. Furthermore, its position is that mandatory vaccination should occur only once other, milder measures, such as the provision of information and encouragement, have been exhausted. In any event, if mandatory vaccination is to take place, it must be targeted and time-limited. The reason for this, according to the Committee, is because vaccination constitutes an intense, interventionist act on the body of a person, which is something that cannot be overlooked. Moreover, it is pointed out that making vaccination mandatory entails the danger of diminishing trust in public health institutions or even causing reactions that may reignite any prior existing anti-vaccine movements (Bioethics and Technoethics Committee, Recommendation). Considering these risks, it might be preferable to strongly recommend something, rather than impose it.

The above positions are entirely reasonable, take into account the seriousness of the matter at hand and leave it to the discretion of the acting regulatory administration to adopt further measures, should the need for establishing mandatory vaccination be found to be imperative. Assessing whether compulsory vaccination should also be applied to other professions, rather than be solely confined to those related to health care, would be an even more functional approach. This category could include, for instance, police officers, those working in services providing food and drink, theatres, and so on.

Bearing in mind the above, for the measure of mandatory vaccination to be proportionate, the following must apply: Firstly, vaccination should not be physically imposed: a doctor cannot be chasing us with a syringe to administer the vaccine. Something like this would violate the value of the human person. Notwithstanding the above, non-vaccination could be linked to administrative penalties, such as monetary fines or prohibiting access to certain specified public areas or services (Haralabos Anthopoulos, 2020). Secondly, vaccination cannot be imposed if it is not accessible to the entire population, meaning that it cannot be made mandatory if it is not available. In the event vaccination is not accessible to everyone, non-vaccination cannot entail negative consequences. Thirdly, to render vaccination compulsory, this must be preceded by the conduction of wide-ranging epidemiological studies showing that it does not cause negative side effects beyond those expected. Given the lack of such studies when it comes to children, for example, vaccination may not be made mandatory to attend lessons, and nonvaccination cannot constitute a reason for not allowing pupils into schools. Fourthly, vaccination could be imposed for specified population groups and not to the entire population without exception. Some cases in point could be health care professionals, care home 
residents, those working in the food industry, etc. In this respect, it would be crucial for the legislator to predetermine these specific population groups.

Taking into consideration the grave risks posed by COVID-9, both concerning the health of each individual but also vis-a-vis public health, the essential constitutional question is not whether generally imposed compulsory vaccination is constitutionally permissible, but whether it is, in fact, constitutionally necessary: in this sense, what we should also consider is whether the omission on the part of the state to impose compulsory vaccination may be unconstitutional (Haralabos Anthopoulos, 2020).

\section{b) Compulsory Temperature Screening and Medical Testing in General}

At first glance, the compulsory temperature screening of the population, as well as mandatory medical testing, in general, appears to conflict with the right to self-determination. Following a calm and thoughtful approach, in the Guidelines that it published on 18 March 2020, the Hellenic Data Protection Authority (HDPA, Guidelines of 18.03.2020) did not endorse an explicit prohibition of temperature checks of employees by their employers, or the installation of thermal cameras in the workplace, in contrast with other European supervisory authorities. On the contrary, it represented that no measure taken to protect health and safety at work, which includes the processing of the personal data of employees, should be discarded from the outset, so long as the measures adopted comply with the regulations set out by the legislation on data protection and the constitutional principle of proportionality.

More specifically, the installation of thermal cameras constitutes a drastic measure that aims at preventing the entry of persons who have a high temperature into workplaces, even though this does not necessarily mean that these persons have contracted the coronavirus. Automated, large-scale processing of special categories of personal data takes place through the use of such cameras, as data concerning identifiable persons is being collected and recorded (Fereniki Panagopoulou-Koutnatzi, 2020). Therefore, even if said data is not stored in a file, the legislation on personal data protection is applicable in this case due to the occurrence of automated data processing, under to Article 2, paragraph 1 of the General Data Protection Regulation. Under "normal circumstances" the adoption of this measure would have been deemed disproportionate and, as such, it would have been prohibited. Nevertheless, given the status of the current global pandemic that has persisted, and given the overall efforts towards the prevention of the spreading of the virus, the measure above is found to be appropriate and effective for the protection of the health of employees, as well as for safeguarding public health in general. At the same time, it is indubitable that serious concerns also arise about the impact that the adoption of such an approach may have on the protection of the personal data of employees and those entering workplaces; therefore, careful planning of the use of thermal cameras by employers is of paramount importance. Firstly, this measure must be implemented solely and exclusively during the period of the outbreak of the disease. Secondly, data must not be stored in a file. The person responsible for the camera ought to check it in real-time and intervene to prevent entry to anyone who appears to have a high temperature. In case the person who has a high temperature is an employee, the individual responsible for the camera should notify the occupational doctor to activate the application of the relevant procedures. Thirdly, only specific individuals should have access to the camera screen. Fourthly, the thermal camera may only be placed at the entrance of the workplace, and not in any other area therein. Fifthly, the data of the person having a high temperature must not, in any way, be leaked to the remaining personnel; the processing of relevant data must take place by specially authorized staff who will be under the subordination of the occupational doctor. In any event, it is highlighted that the installation of thermal cameras is considered as a "last resort" measure for employers when no milder measures for the protection of the health of employees are available (Fereniki Panagopoulou-Koutnatzi, 2020).

Furthermore, the mandatory medical testing of persons arriving in Greece is, in principle, putting the right to self-determination to the test. In this case, there is an issue when it comes to the validity of the consent granted by the individual in question, given that the alternative would be something potentially onerous for this person, i.e. not being able to enter the Greek territory. Entry to the country may be for reasons of tourism, entertainment and also work. It is, however, noted that such testing does not take place forcefully in a manner that is disrespectful to human value. Given this, it would be sensible to offset the right to selfdetermination with other, equally important constitutional rights.

In the context of assessing the principle of proportionality, it would be crucial to determine whether a measure is appropriate for the protection of public health in conjunction with balanced economic development. It is deemed that sample checking constitutes an appropriate measure, as proceeding in this manner will prevent entry of COVID-positive visitors to our country. Following this, a less onerous yet equally effective measure may be sought. For instance, a less burdensome option would be submitting a recent certificate evidencing a negative COVID-19 test result. According to the above, such an approach is provided for by legislation, but only as an additional measure, given that another condition is also required, namely 
that of sample medical testing. This is because a negative result certificate does not guarantee that the person in question is not COVID-positive at the time of entry into the country. Moreover, many other issues arise regarding the reliability of such test results, as the existence of fake test certificates has also been documented (Proto Thema, 14.07.2020).

Another alternative to compulsory medical testing of persons entering Greece would be closing the borders to prevent the transmission of the disease. If this option were to be followed, the right to selfdetermination would not be violated. Still, the economic development that has already been adversely affected financially would be even more gravely impacted. In addition to the above, denying entry to the country may not take place for reasons of public health or the health of citizens (Athanassios Raikos, 2011). Consequently, restrictive measures may be imposed on a Greek citizen who is COVID-positive, but entry to the country itself may not be refused.

Bearing this in mind, with the only exception being the vaccination certificate issued to those who have been vaccinated, there cannot be a milder but equally effective method under the current circumstances. In this sense, sample medical testing during the period of the pandemic is the only method through which we may attain a balance between the rights to health, economic development, selfdetermination, and the private life of individuals. The obligation to provide a recent negative COVID test result at the time of entry from an area of the country where there are many cases is also in support of this method.

\section{c) The Issue of use of Experimental Drugs}

Given the lack of drugs for the treatment of COVID, we are also faced with the question of whether a drug that is used for treating other diseases may be administered to patients who have coronavirus when its effectiveness for treating the new coronavirus is not scientifically proven and, thus, it remains doubtful. We will not consider the framework of clinical testing in general (Dimitra Papadopoulou-Klamari, 2014), but rather the need to set up an emergency legislative framework in particular. More specifically, we must enquire whether, in the light of the current emergency circumstances, it would contravene fundamental principles of bioethics if the administration of drugs, beyond their recommended uses, to patients suffering from COVID-19 by attending physicians were to be allowed. The answer to this question may only be given in the context of a situation that must be deemed exceptional. If we were to wait for a long time to assess the effectiveness and suitability of a drug, this pandemic could well end up being a tragedy. The risk of facing a situation as onerous as what Italy and Spain experienced in terms of the spreading of the virus is not small at all, as time is running in a very threatening manner against us. The basic criteria for the granting of a "green light" to the exceptional speeding up of the otherwise lengthy processes that guarantee the good standing of experimental drugs in periods of "normality", are the following: the granting of informed consent on the part of the patient or by his next of kin, when the patient is unable to grant consent; the certainty that these drugs will not cause harm and, in the worst-case scenario, they will simply not be helpful; the approval of the attending doctor and, following this, that of the special hospital committee before their administration. Given the above, the answer to the question is that procedures may be accelerated in emergencies, provided that the fundamental principles concerning the conduction of clinical trials will not be circumvented (Dimitra Papadopoulou-Klamari, 2014).

\section{d) Making the Wearing of Face Masks Mandatory}

Legislative provisions making the wearing of face masks compulsory, particularly in schools, gives rise to the question of whether an individual has the right not to wear a mask and incite other people to do the same. The answer to this could certainly be provided to us by Kant: according to him, legal order constitutes a right in itself. "There can be no justified resistance on the part of the people against the legislative authority of the state. A state governed by the rule of law is only strong when universal subordination to its legislative will exists $[\ldots]$. The reason why it is the duty of people to tolerate even what is the most intolerable misuse of supreme power is that it is impossible even to conceive of their resistance to the supreme legislation as being anything other than unlawful and liable to nullify the entire legal constitution" (Immanuel Kant, 1970). It is clearly contradictory, according to Kant, for a legal order to provide the ability to resist its mandates, as this essentially self-negates its supreme authority. This reasoning is only founded when the legal order in question has democratic legitimacy (Stavros Tsakyrakis, 2012). In a tyrannical regime, where citizens are excluded from the legislative process, there is no issue of obligation of obedience to a heteronomous legal order, and each individual has a right to resist, as well as a right to revolt against it (Stavros Tsakyrakis, 2012). In a democratic regime, on the other hand, one may express his discontent and voice his views openly. Still, he has no right not to obey, particularly when the law concerns a fundamental right about public health. This is not at all an issue of conflict between natural and statute law. Not complying with rules on hygiene is not related to natural laws. Mask deniers are not in agreement with a certain legislative provision, which is based on research data. It should not escape our attention that, in the same way, they could also disagree with the use of face masks by doctors in surgery, the use of gloves by bread makers during a pandemic, the use of protective equipment by visitors entering 
intensive care units, and so on. They do not purport that masks constitute discrimination against the lower layers of society but rather put forward their disagreement with a scientific finding. In the case at hand, and to begin with, scientists ought to make a convincing case to people based on substantiated arguments.

Nevertheless, if a person decides not to wear a mask without having a medical reason for doing so, then it is wholly reasonable that he should be the recipient of the lawful ramifications of the prohibition of entry to the area specified. Therefore, a pupil will be justly denied entry to a classroom, as will a customer to an indoor cinema theatre, a citizen to a public service, a shop and, even more to the point, to a hospital. Indeed, this is the case as the person in question is unable to support his scientific disagreement. Furthermore, if a person is inciting the public to collective disobedience against the use of masks, which is something required by law in certain circumstances, then it is reasonable that he should face the legal consequences set out in the penal code, under Article 183 of the New Greek Penal Code.

For the above to become more intelligible, the following conclusions could be reached (Fereniki Panagopoulou-Koutnatzi, 2021):

a) The position of "I find the use of masks in schools ineffective, whereas children will not comply with it and thus more problems will be created" is a constitutionally permissible expression of opinion.

b) The position of "I find the use of masks unconstitutional" is also a constitutionally permissible expression of opinion.

c) The position of "do not send your children to school wearing a mask" constitutes incitement to disobedience against a specific provision of the law which, particularly during the period of the pandemic, falls outwith the permissible boundaries of freedom of speech.

d) Not using a mask during the period of a pandemic, when wearing one is mandatory as a matter of law, does not constitute civil disobedience in the spirit of what has been set out above: instead, it is unlawful and, most crucially, antisocial behavior.

\section{e) The Question of Individual Responsibility}

The implementation of measures on the part of the state does not, in itself, suffice for the effective protection of public health and, specifically, for managing the pandemic; on the contrary, it requires the activation of individual responsibility by each one of us (Hellenic Bioethics Committee, Recommendation of 17.03.2020). It is a fact that if citizens do not comply with recommendations and the relevant legal provisions relating to the avoidance of social interaction if they do not stop behaving as if they were COVID-positive by being extra vigilant against transmitting the virus to someone else, and if they do not assume their share of responsibility, no state intervention will ever be effective. It is also a fact that if citizens do not perceive voluntarism as an integral part of their responsibility, our society will not overcome this crisis.

This idea of individual responsibility, which stems from notions of Protestant ethics, is provided in Article 25, paragraph 4 of the Constitution (Nikos K. Alivizatos, 2020), according to which "The State has the right to claim of all citizens to fulfill the duty of social and national solidarity". In the light of this provision, the society of citizens has a prime opportunity to assume its share of responsibility and assist in inhibiting the spreading of the virus (Nikos K. Alivizatos, 2020). The meaning of the concept of solidarity that is referred to in the above Article constitutes the ratio of the entire sum of a citizen's constitutional duties, the fulfillment of which is strongly called for by the Constitution, due to their enhanced importance for organized social coexistence (Haralabos Anthopoulos, 2017). This provision is not a rule for the legal production of new fundamental duties beyond those expressly set out in the Constitution (Haralabos Anthopoulos, 2017). One of these duties is the adoption of individual measures towards the protection of public health.

The activation of this sense of social solidarity, however, must be supported through the provision of accurate and reliable information to the public, along with timely and immediate reaction against the provision of misleading information (Hellenic Bioethics Committee, Recommendation of 17.03.2020). Moreover, individual responsibility is augmented through the promotion, as role models, of people in the first line of the fight against the pandemic, who have an increased sense of duty when it comes to striving for the protection of public health (Hellenic Bioethics Committee, Recommendation of 17.3.202).

This obligation of showing social and national solidarity, as enshrined in Article 25, paragraph 4 of the Constitution, may be activated in particularly critical circumstances, such as those present in the situation we are currently facing, and may include mandatory vaccination, making the wearing of a face mask compulsory, the conduction of medical testing, etc. It is also a fact that our Constitution includes an explicit obligation of social and national solidarity, among other duties (such as, for example, the duty to resist against anybody who tries to subvert the Constitution violently, under Article 120, paragraph 4; the obligatory exercise of the right to vote, provided in Article 51, paragraph 5; compulsory schooling, which may not be less than nine years, stipulated by Article 16, paragraph 3; the duty of all Greek citizens, without exception, to contribute towards sharing the burden of public expenditure according to their ability, as seen in Article 4, paragraph 5; and the obligation of every Greek citizen able to bear arms to assist in the defense of the nation, as provided by law, set out in Article 4, paragraph 6). One of the 
duties of citizens towards social solidarity is to contribute, to the extent permitted by one's capabilities, to the creation of the so-called "great wall of immunity against the virus" to assist in the reduction of the number of deaths and of those who will be infected. In this way, we will offer our public health systems the opportunity to take a big breath, so to speak, as well as allow educational, cultural, financial, and social activities to flourish once again.

\section{iil. In Lieu of an Epilogue}

Constitutional lawyers are not the protagonists of developments during the current situation that we are all facing. At the present instance, it would be wiser if they assumed the position of second fiddle. First place today is justly awarded to those doctors, researchers, nursing staff and all the other unsung heroes who are fighting in the first line for the protection of the most valuable of all goods, namely that of public health. Once the fight for life and health is won, constitutional lawyers may take the reins and determine that the character of restrictive measures and healthcare policies adopted in periods of crisis, when a prime opportunity for their formulation presented itself because of the pandemic, is one of extraordinariness (Spyros Vlachopoulos, 29.03.2020). Notwithstanding the above, it is also imperative to commence a discussion on whether the time has well and truly come to transform our state into one of prevention, where the interests of the public as a whole will take genuine precedence over individual interests (Haralabos Anthopoulos, 2005 and 2020). Indeed, this is a subject matter that requires a lot of attention and serious reflection. It is beyond doubt that we need to carve out a policy for addressing disasters, but we should not transform our state based on the occurrence of an incident of an emergency. What we can do, however, is make good use of one of the main teachings of the pandemic, which is that of the importance of education on matters of bioethics.

\section{List of Publications}

1. James H. Marsh, The Canadian Encyclopedia, The 1885 Montreal Smallpox Epidemic, 2.04.2013 (updated 4.3.2015), available at: https://www.the canadianencyclopedia.ca/en/article/plague-the-reddeath-strikesmontreal-feature

2. Stewart Lyman, Pharma's tarnished reputation helps fuel the anti-vaccine movement, 26.02.2019, available at: https://www.statnews.com/2019/02/26/ anti-vaccine-movement-pharma-tarnishedrepute tionn/

3. Hellenic Bioethics Committee, Recommendation, Immunization in Children, 26.05.2015, available at: http://www.bioethics.gr/images/pdf/GNOMES/REC OMMENDATION_Immunizatin_In_Children_Fina_G R.pdf
4. Vassiliki Mollaki, Child vaccination: Selfdetermination or protection of public health? Bioethical issues and proposals of the Hellenic Bioethics Committee, in: Maria Kanellopoulou Botti/ Fereniki Panagopoulou-Koutnatzi (edit.), Bioethical issues III, The Child, "Papazissi" Editions, Athens 2018, p. 349 et seq.

5. Bioethics and Technoethics Committee, Recommendation on the obligation of vaccination in certain professional groups within the health care sector.

6. Haralabos Anthopoulos, Vaccine: The Limits of NonCompulsory, "Proto Thema" newspaper,11.12.2020, available at: https://www.protothema.gr/blogs/ haralabos-anthopoulos/article/1073847/emvolio-ta oria-tis-mi-upohreotikotitas/

7. Hellenic Data Protection Authority (HDPA), Guidelines for the processing of personal data in the context of COVID-19 management, 18.03.2020, available at: https://www.dpa.gr/APDPXPortlets/ht docs/documentSDisplay.jsp?docid=163,39,44,01, 194,223,3,99

8. Fereniki Panagopoulou-Koutnatzi, The protection of personal data during a pandemic, available at: https://www.constitutionalism.gr/2020-03-28_pana gopoulou-privacy-koronavirus/

9. Fereniki Panagopoulou-Koutnatzi, The protection of personal data in the coronavirus era, Syntagma Watch, 17.03.2020, available at: https://www. syntagmawatch.gr/trending-issues/i-prostasia-tonprosopikondedomenon-stin-epoxi-toukoronoiou/

10. Coronavirus-Promachonas [border-crossing]: On sale, fake negative test certificates for 40 euros, Proto Thema, 14.07.2020, available at: https://www. protothema.gr/greece/article/1026537/koronoiospromahonas-poulounplasta-pistopoiitika-arnitikontest-gia-40-euro/

11. Athanassios Raikos, Constitutional Law, Fundamental Rights, $4^{\text {th }}$ Edition, Nomiki Vivliothiki, Athens 2011, p. 490.

12. Dimitra Papadopoulou-Klamari, Clinical testing, in: Maria Kanellopoulou-Botti/Fereniki PanagopoulouKoutnatzi (edit.), Medical Responsibility and Bioethics, Contemporary Approaches and Future Prospects, Editions Broken Hill, Paschalidis, Nicosia 2014, p. 163 et seq.

13. Immanuel Kant, The Metaphysics of Morals, in: Political Writings, Cambridge, 1970, p. 144.

14. Stavros Tsakyrakis, Civil Disobedience, Lifo, 2.12.2012, available at: https://www.lifo.gr/team/ readersdigest/33981

15. Fereniki Panagopoulou-Koutnatzi, On the deniers of the face mask, Syntagma Watch, 4.9.2021, available at: https://www.syntagmawatch.gr/trending-issues/ peri-ton-arniton-tis-maskas/.

16. Hellenic Bioethics Committee, Recommendation, The bioethical dimension of individual responsibility 
in the treatment of COVID 19 (coronavirus), 17.03.2020, available at: http://www.bioethics.gr/ images/pdf/GNOMES/Recommendation_coronaviru s_FINLGR.pdf\%20.

17. Nikos K. Alivizatos, Which Democracy after Covid19? "Kathimerini" newspaper, 25.03.2020, available at: https://www.kathimerini.gr/society/1070545/nalivizatos-poia-dimokratia-meta-toncovid-19/

18. Haralabos Anthopoulos, Interpretation of Article 25 of the Constitution, in: Filippos Spyropoulos/ Xenophon Kontiadis/Haralabos Anthopoulos/ Giorgos Gerapetritis (edit.), the Constitution, Interpretation Article by Article, "Sakoulas" Editions, Athens-Thessalonica 2017, p. 684 et seq.

19. Spyros Vlachopoulos, "No" to constitutional mithridatism, Kathimerini newspaper, 29.03.2020, available at: https://www.kathimerini.gr/opinion/107 1326/ochi-ston-syntagmatiko-mithridatismo/

20. Haralabos Anthopoulos, State of prevention and right to security, in: Haralabos Anthopoulos/ Xenophon Kontiadis/Theodoros Papatheodorou (edit.), Security and rights in a society of risk, "Ant. N. Sakkoulas" Editions, Athens - Komotini, 2005, p. 109 et seq.

21. Haralabos Anthopoulos, Covid-19 and the era of rights, 28.03.2020, available at: https://www. constitutionalism.gr/2020-03-29_anthopoulos-covid 19-telos-epohis-dikaiomaton/ 